ISSN 2078-3744. Вісник Львів. ун-ту. Серія мех.-мат. 2018. Випуск 85. С. 82-90

Visnyk of the Lviv Univ. Series Mech. Math. 2018. Issue 85. P. 82-90

http://publications.lnu.edu.ua/bulletins/index.php/mmf

doi: http://dx.doi.org/10.30970/vmm.2018.85.082-090

УДК $517.53+519.213 .2$

\title{
ON THE BELONGING OF ANALYTIC IN UNIT DISK \\ CHARACTERISTIC FUNCTIONS OF PROBABILITY LAWS TO GENERALIZED CONVERGENCE CLASS
}

\author{
Oksana Mulyava $^{1}$, Myroslav Sheremeta ${ }^{2}$ \\ ${ }^{1}$ Kyiv National University of Food Technologies, \\ Volodymyrska Str., 68, 01004, Kyiv, Ukraine \\ e-mail:info@nuft.edu.ua \\ ${ }^{2}$ Ivan Franko Lviv National University, \\ Universitetska Str., 1, 79000, Lviv, Ukraine \\ e-mail:m.m.sheremeta@gmail.com
}

For continuous on $\left[x_{0},+\infty\right)$ functions $\alpha$ and $\beta$ increasing to $+\infty$ we say that an analytic in $\mathbb{D}=\{z:|z|<1\}$ characteristic function $\varphi$ of a probability law $F$ belongs to the generalized convergence $\alpha \beta$-class if $\int_{r_{0}}^{1} \frac{\alpha(\ln M(r, \varphi))}{(1-r)^{2} \beta\left(\frac{1}{1-r}\right)} d r<+\infty$, where $M(r, \varphi)=\max \{|\varphi(z):| z \mid=r\}$. Conditions on $\alpha, \beta$ and $F$ are found under which the function $\varphi$ belongs to the generalized convergence $\alpha \beta$-class if and only if $\int_{x_{0}}^{\infty} \alpha^{\prime}(x) \beta_{1}\left(\frac{x}{\ln \left(W_{F}(x) e^{x}\right)}\right) d x<+\infty$, where $\beta_{1}(x)=\int_{x}^{\infty} \frac{d t}{\beta(t)}$ and $W_{F}(x)=1-F(x)+F(-x)$.

Key words: analytic function, probability law, characteristic function, generalized convergence class.

\section{INTRODUCTION}

A continuous on the left on $(-\infty,+\infty)$ non-decreasing function $F$ is said [1, p. 10] to be a probability law if $\lim _{x \rightarrow+\infty} F(x)=1$ and $\lim _{x \rightarrow-\infty} F(x)=0$, and the function $\varphi(z)=$ $\int_{-\infty}^{\infty} e^{i z x} d F(x)$ defined for real $z$ is called [1, p. 12] a characteristic function of this law. If $\varphi$ has an analytic continuation on the disk $\mathbb{D}=\{z:|z|<1\}$ then we call $\varphi$ an analytic in

2010 Mathematics Subject Classification: 30B50, 60E10

(C) Mulyava, O., Sheremeta, M., 2018 
$\mathbb{D}$ characteristic function of the law $F$. Further we always assume that $\mathbb{D}$ is the maximal disk of the analicity of $\varphi$. It is known [1, p. 37-38] that $\varphi$ is an analytic in $\mathbb{D}$ characteristic function of the law $F$ if and only if for every $r \in[0,1)$

$$
W_{F}(x)=: 1-F(x)+F(-x)=O\left(e^{-r x}\right), \quad x \rightarrow+\infty .
$$

Hence it follows that

$$
\varliminf_{x \rightarrow+\infty} \frac{1}{x} \ln \frac{1}{W_{F}(x)}=1 .
$$

For $0 \leq r<1$ we put $M(r, \varphi)=\max \{|\varphi(z)|:|z|=r\}$, and if $\varphi$ has the order

$$
\varrho=\varlimsup_{r \uparrow 1} \frac{\ln \ln M(r, \varphi)}{-\ln (1-r)}>0
$$

a convergence class is defined [2] by the condition

$$
\int_{r_{0}}^{1}(1-r)^{\varrho-1} \ln M(r, \varphi) d r<+\infty .
$$

For $\varrho=2$ this condition is sufficient [3, p. 50] in order that $\varphi$ belong to the class of Mac-Lane.

For an analytic in $\mathbb{D}$ characteristic function $\varphi$ of the order $\varrho>0$ in [4] it is proved that in order that $\varphi$ belong to convergence class it is necessary and in the case when the function $v(x)=\ln \frac{1}{W_{F}(x)}$ is continuously differentiable and $v^{\prime}$ increases it is sufficient that

$$
\int_{x_{0}}^{\infty}\left\{\left(1+\frac{1}{x} \ln W_{F}(x)\right)^{+}\right\}^{\varrho+1} d x<+\infty .
$$

Generalizing this result in [5] the concept of the convergence $\Phi$-class is introduced as follows.

Let $\Omega(1)$ be the class of positive unbounded on $(0,1)$ functions $\Phi$ such that the derivative $\Phi^{\prime}$ is positive continuously differentiable and increasing to $+\infty$ on $(0,1)$.

As in [5], we say that $\varphi$ belongs to a convergence $\Phi$-class if

$$
\int_{r_{0}}^{1} \frac{\Phi^{\prime}(r) \ln M(r, \varphi)}{\Phi^{2}(r)} d r<+\infty
$$

and by $V(1)$ we denote the class of positive continuously differentiable on $(0,+\infty)$ functions $v$ such that $v^{\prime}(x) \uparrow 1$ as $x \rightarrow+\infty$.

The following theorem was proved in [5].

Theorem 1. Let $\Phi \in \Omega(1), \frac{\Phi^{\prime}(r)}{\Phi(r)}$ be a function, nondecreasing on $\left[r_{0}, 1\right), \Phi^{\prime}(r)>\frac{1}{1-r}$ $\Phi^{\prime}\left(r+\frac{1}{\Phi^{\prime}(r)}\right) \leq H_{1} \Phi^{\prime}(r)$ and $\frac{\Phi^{\prime \prime}(r) \Phi(r)}{\left(\Phi^{\prime}(r)\right)^{2}} \leq H_{2}$ for all $r \in\left[r_{0}, 1\right)$, where $H_{j}=$ const $>$ 
0 , and $\int_{r_{0}}^{1} \frac{\Phi^{\prime}(r) \ln \Phi^{\prime}(r)}{\Phi^{2}(r)} d r<+\infty$. Suppose that $\varphi$ is an analytic in $\mathbb{D}$ characteristic function on a probability law $F$ such that $\varlimsup_{x \rightarrow+\infty} W_{F}(x) e^{x}=+\infty$.

Then in order that $\varphi$ belong to a convergence $\Phi$-class it is necessary and, in the case when $\ln \frac{1}{W_{F}(x)}=v(x) \in V(1)$, it is sufficient that

$$
\int_{x_{0}}^{\infty} \frac{d x}{\Phi^{\prime}\left(\frac{1}{x} \ln \frac{1}{W_{F}(x)}\right)}<+\infty .
$$

Corollary 1. Let $0<\varrho<+\infty$ and $\varphi$ be an analytic in $\mathbb{D}$ characteristic function of a probability law $F$ such that $\varlimsup_{x \rightarrow+\infty} W_{F}(x) e^{x}=+\infty$. Then in order that (3) holds it is necessary and, in the case when $\ln \frac{1}{W_{F}(x)}=v(x) \in V(1)$, it is sufficient that

$$
\int_{x_{0}}^{\infty}\left(\frac{\ln \left(W_{F}(x) e^{x}\right)}{x}\right)^{\varrho+1} d x<+\infty .
$$

Let $L$ be a class of continuous increasing functions $\alpha$ such that $\alpha(x) \geq 0$ for $x \geq x_{0}$, $\alpha(x)=\alpha\left(x_{0}\right)$ for $x \leq x_{0}$ and on $\left[x_{0},+\infty\right)$ the function $\alpha$ increases to $+\infty$. We say that $\alpha \in L^{0}$ if $\alpha \in L$ and $\alpha(x(1+o(1)))=(1+o(1)) \alpha(x)$ as $x \rightarrow+\infty$.

Let $\alpha \in L$ and $\beta \in L$. We say that an analytic in $\mathbb{D}$ function $\varphi$ belongs to the generalized convergence $\alpha \beta$-class, if

$$
\int_{r_{0}}^{1} \frac{\alpha(\ln M(r, \varphi))}{(1-r)^{2} \beta\left(\frac{1}{1-r}\right)} d r<+\infty
$$

If $\alpha(x) \equiv x$ and $\beta \equiv x^{\varrho+1}$ for $x_{0} \leq x<+\infty$ then $(7)$ implies (3). Here we examine a problem of the belonging of the analytic characteristic function of probability law to the generalized convergence $\alpha \beta$-class.

\section{Auxiliary results}

Let $I(r, \varphi)=\int_{0}^{\infty} W_{F}(x) e^{x r} d x$ and $\mu(r, \varphi)=\sup \left\{W_{F}(x) e^{x r}: x \geq 0\right\}$ be the maximum of integrand. Suppose that $M(r, \varphi) \uparrow+\infty$ as $r \uparrow 1$. Then [5]

$$
\ln \mu(r, \varphi) \leq(1+o(1)) \ln M(r, \varphi) \leq(1+o(1)) \ln I(r, \varphi), \quad r \uparrow 1 .
$$

Hence it follows that if $\alpha \in L^{0}$ then

$$
\int_{r_{0}}^{1} \frac{\alpha(\ln \mu(r, \varphi))}{(1-r)^{2} \beta\left(\frac{1}{1-r}\right)} d r \leq \int_{r_{0}}^{1} \frac{\alpha(\ln M(r, \varphi))}{(1-r)^{2} \beta\left(\frac{1}{1-r}\right)} d r \leq \int_{r_{0}}^{1} \frac{\alpha(\ln I(r, \varphi))}{(1-r)^{2} \beta\left(\frac{1}{1-r}\right)} d r .
$$


On the other hand

$$
\begin{aligned}
I(r, \varphi)=\int_{0}^{\infty} W_{F}(x) e^{x r} d x & =\int_{0}^{\infty} W_{F}(x) \exp \left\{\frac{r+1}{2} x\right\} \exp \left\{-\frac{1-r}{2} x\right\} d x \leq \\
& \leq \mu\left(\frac{r+1}{2}, \varphi\right) \frac{2}{1-r} .
\end{aligned}
$$

In [6] it is proved that if $\alpha \in L^{0}$ then $\alpha$ is $R O$-varying and, thus [7, p. 86], $1 \leq \alpha(l x) / \alpha(x) \leq M(l)<+\infty$ for each $l \in[1,+\infty)$ and all $x \geq x_{0}(l)$. Therefore, from (9) we obtain

$$
\begin{aligned}
& \alpha(\ln I(r, \varphi)) \leq \alpha\left(2 \max \left\{\ln \mu\left(\frac{r+1}{2}, \varphi\right), \ln \frac{2}{1-r}\right\}\right) \leq \\
& \leq M(2) \alpha\left(\max \left\{\ln \mu\left(\frac{r+1}{2}, \varphi\right), \ln \frac{2}{1-r}\right\}\right)= \\
& =M(2)\left(\max \left\{\alpha\left(\ln \mu\left(\frac{r+1}{2}, \varphi\right)\right), \alpha\left(\ln \frac{2}{1-r}\right\}\right)\right) \leq \\
& \leq M(2)\left(\alpha\left(\ln \mu\left(\frac{r+1}{2}, \varphi\right)\right)+\alpha\left(\ln \frac{2}{1-r}\right)\right),
\end{aligned}
$$

whence for $\beta \in L^{0}$ using the cite of result from [6] we obtain

$$
\begin{gathered}
\int_{r_{0}}^{1} \frac{\alpha(\ln I(r, \varphi))}{(1-r)^{2} \beta\left(\frac{1}{1-r}\right)} d r \leq M(2)\left(\int_{r_{0}}^{1} \frac{\alpha\left(\ln \mu\left(\frac{r+1}{2} \varphi\right)\right)}{(1-r)^{2} \beta\left(\frac{1}{1-r}\right)} d r+\int_{r_{0}}^{1} \frac{\alpha\left(\ln \frac{2}{1-r}\right)}{(1-r)^{2} \beta\left(\frac{1}{1-r}\right)} d r\right)= \\
=2 M(2) \int_{r_{0}}^{1} \frac{\alpha\left(\ln \mu\left(\frac{r+1}{2}, \varphi\right)\right)}{4(1-(r+1) / 2)^{2} \beta\left(\frac{1}{2(1-(r+1) / 2)}\right)} d \frac{r+1}{2}+M(2) \int_{r_{0}}^{1} \frac{\alpha\left(\ln \frac{2}{1-r}\right)}{(1-r)^{2} \beta\left(\frac{1}{1-r}\right)} d r \leq \\
\leq K_{1} \int_{t_{0}}^{1} \frac{\alpha(\ln \mu(t, \varphi))}{(1-t)^{2} \beta\left(\frac{1}{1-t}\right)} d t+K_{2} \int_{x_{0}}^{\infty} \frac{\alpha(\ln x)}{\beta(x)} d x .
\end{gathered}
$$

From $(9)$ and $(10)$ the following statement follows.

Proposition 1. Let $\alpha \in L^{0}, \beta \in L^{0}$ and $\int_{x_{0}}^{\infty} \frac{\alpha(\ln x)}{\beta(x)} d x<+\infty$. Then (7) holds if and only if

$$
\int_{r_{0}}^{1} \frac{\alpha(\ln \mu(r, \varphi))}{(1-r)^{2} \beta\left(\frac{1}{1-r}\right)} d r<+\infty
$$


The function $\ln \mu(r, \varphi)$ may be bounded. It is easy to show that $\mu(r, \varphi) \leq K<+\infty$ for all $r \in[0,1)$ if and only if $W_{F}(x) e^{x} \leq K<+\infty$ for all $x \geq 0$. Thus, $\mu(r, \varphi) \uparrow+\infty$ as $r \uparrow 1$ if and only if $\varlimsup_{x \rightarrow+\infty} W_{F}(x) e^{x}=+\infty$. In [5] was proved that the function $\ln \mu(r, \varphi)$ is convex on $[0,1)$ and there exists a nondecreasing on $[0, R)$ function $\nu(r, \varphi)$ such that $(\ln \mu(r, \varphi))^{\prime}=\nu(r, \varphi)$ for all $r \in(0, R)$ with the exception of an at most countable set, i.e.

$$
\ln \mu(r, \varphi)=\ln \mu\left(r_{0}, \varphi\right)+\int_{r_{0}}^{r} \nu(x, \varphi) d x, \quad 0 \leq r_{0} \leq r<1 .
$$

Hence it follows that if $\mu(r, \varphi) \uparrow+\infty$ as $r \uparrow 1$ then $\nu(r, \varphi) \nearrow+\infty$ as $r \uparrow 1$.

If $\ln \frac{1}{W_{F}(x)}=v(x) \in V(1)$ then for every $r \in(0,1)$ the function $\ln W_{F}(x)+r x=$ $=-v(x)+r x$ has a unique point of the maximum $x=\nu(r, \varphi)$, which is a continuous on $(0,1)$ function increasing to $+\infty$, and

$$
\ln \mu(r, \varphi)=\max \left\{\ln W_{F}(x)+r x: x \geq 0\right\}=\ln W_{F}(\nu(r, \varphi))+r \nu(r, \varphi),
$$

whence

$$
\frac{1}{\nu(r,, \varphi)} \ln \frac{1}{W_{F}(\nu(r, \varphi))}=r-\frac{\ln \mu(r, \varphi)}{\nu(r, \varphi)} \leq r .
$$

From 12 it follows that

$$
\ln \mu(r, \varphi)=\ln \mu\left(r_{0}, \varphi\right)+\nu(r, \varphi)\left(r-r_{0}\right) \leq \ln \mu\left(r_{0}, \varphi\right)+\left(1-r_{0}\right) \nu(r, \varphi),
$$

and if $\alpha \in L^{0}$ then $\alpha(\ln \mu(r, \varphi)) \leq K_{1} \alpha\left(\nu(r, \varphi)\right.$ for all $r \in\left[r_{0}, 1\right)$.

On the other hand for $r \geq r_{0}$

$$
\ln \mu\left(\frac{1+r}{2}, \varphi\right) \geq \ln \mu\left(r_{0} \varphi\right)+\int_{r}^{(1+r) / 2} \nu(x, \varphi) d x \geq \ln \mu\left(r_{0}, \varphi\right)+\nu(r, \varphi) \frac{1-r}{2}
$$

and if $\alpha\left(e^{x}\right) \in L^{0}$ then as above we obtain

Thus,

$$
\begin{gathered}
\alpha(\nu(r, \varphi)) \leq \alpha\left(\exp \left\{\ln \frac{2}{1-r}+\ln \ln \mu\left(\frac{1+r}{2}, \varphi\right)\right\}\right) \leq \\
\leq \alpha\left(\exp \left\{2 \max \left\{\ln \frac{2}{1-r}, \ln \ln \mu\left(\frac{1+r}{2}, \varphi\right)\right\}\right\}\right) \leq \\
\leq K_{2}\left(\alpha\left(\ln \mu\left(\frac{1+r}{2}, \varphi\right)\right)+\alpha\left(\ln \frac{2}{1-r}\right)\right) .
\end{gathered}
$$

$$
\begin{gathered}
\int_{r_{0}}^{1} \frac{\alpha(\ln \mu(r, \varphi))}{(1-r)^{2} \beta\left(\frac{1}{1-r}\right)} d r \leq K_{1} \int_{r_{0}}^{1} \frac{\alpha(\ln \nu(r, \varphi))}{(1-r)^{2} \beta\left(\frac{1}{1-r}\right)} d r \leq \\
\leq K_{1} K_{2} \int_{r_{0}}^{1} \frac{\alpha(\ln \mu((r+1) / 2, \varphi))}{(1-r)^{2} \beta\left(\frac{1}{1-r}\right)} d r+K_{1} K_{2} \int_{r_{0}}^{1} \frac{\alpha(\ln (2 /(1-r)))}{(1-r)^{2} \beta\left(\frac{1}{1-r}\right)} d r,
\end{gathered}
$$


whence as above we obtain the following statement.

Proposition 2. Let $\alpha\left(e^{x}\right) \in L^{0}, \beta \in L^{0}, \int_{x_{0}}^{\infty} \frac{\alpha(\ln x)}{\beta(x)} d x<+\infty$ and $\ln \frac{1}{W_{F}(x)}=$ $=v(x) \in V(R)$. Then 11 holds if and only if

$$
\int_{r_{0}}^{1} \frac{\alpha(\nu(r, \varphi))}{(1-r)^{2} \beta\left(\frac{1}{1-r}\right)} d r<+\infty
$$

Thus, the problem of belonging of $\varphi$ to the generalized convergence $\alpha \beta$-class is reduced to the problem of the fulfilment of (14).

\section{MAin Result}

Using Propositions 1 and 2 we may prove the following main theorem.

Theorem 2. Let $\alpha\left(e^{x}\right) \in L^{0}, \beta \in L^{0}, \int_{x_{0}}^{\infty} \frac{\alpha(\ln x)}{\beta(x)} d x<+\infty$ and $\frac{x \beta^{\prime}(x)}{\beta(x)} \geq 2+h$ for all $x \geq x_{0}$. Suppose that $\varphi$ is an analytic in $\mathbb{D}$ characteristic function on probability law $F$ such that $W_{F}(0)=1, \ln \frac{1}{W_{F}(x)}=v(x) \in V(1)$ and $\varlimsup_{x \rightarrow+\infty} W_{F}(x) e^{x}=+\infty$.

Then in order that $\varphi$ belongs to a generalized convergence $\alpha \beta$-class it is necessary and sufficient that

$$
\int_{x_{0}}^{\infty} \alpha(x) \beta_{1}\left(\frac{x}{\ln \left(W_{F}(x) e^{x}\right)}\right) d x<+\infty, \quad \beta_{1}(x)=\int_{x}^{\infty} \frac{d t}{\beta(t)} .
$$

Proof. Clearly,

$$
\begin{gathered}
\int_{r_{0}}^{1} \frac{\alpha(\nu(r, \varphi))}{(1-r)^{2} \beta\left(\frac{1}{1-r}\right)} d r=-\int_{r_{0}}^{1} \alpha(\nu(r, \varphi)) d \beta_{1}\left(\frac{1}{1-r}\right)= \\
=-\left.\alpha(\nu(r, \varphi)) \beta_{1}\left(\frac{1}{1-r}\right)\right|_{r_{0}} ^{1}+\int_{r_{0}}^{1} \alpha^{\prime}(\nu(r, \varphi)) \beta_{1}\left(\frac{1}{1-r}\right) d \nu(r, \varphi) .
\end{gathered}
$$

At first we suppose that $(15)$ holds. Then, from $(16)$ and $(13)$, in view of the nonincreasing of $\beta_{1}$, we have

$$
\begin{gathered}
\int_{r_{0}}^{1} \frac{\alpha(\nu(r, \varphi))}{(1-r)^{2} \beta\left(\frac{1}{1-r}\right)} d r \leq K+\int_{r_{0}}^{1} \alpha^{\prime}(\nu(r, \varphi)) \beta_{1}\left(\frac{1}{1-\frac{1}{\nu(r, \varphi)} \ln \frac{1}{W_{F}(\nu(r, \varphi))}}\right) d \nu(r, \varphi)= \\
=K+\int_{x_{0}}^{\infty} \alpha^{\prime}(\nu(r, \varphi)) \beta_{1}\left(\frac{\nu(r, \varphi)}{\ln \left(W_{F}(\nu(r, \varphi) x) e^{\nu(r, \varphi)}\right)}\right) d \nu(r, \varphi)<+\infty,
\end{gathered}
$$

because the function $\nu(r, \varphi)$ is continuous. The sufficiency of 15 is proved. 
Now we prove its necessity. From (14) for each $\varepsilon>0$ and all $r \in\left[r_{0}(\varepsilon), 1\right)$ we have

$$
\varepsilon>\int_{r}^{1} \frac{\alpha(\nu(r, \varphi))}{(1-r)^{2} \beta\left(\frac{1}{1-r}\right)} d r \geq \alpha(\nu(r, \varphi)) \int_{r}^{1} \frac{d r}{(1-r)^{2} \beta\left(\frac{1}{1-r}\right)}=\alpha(\nu(r, \varphi)) \beta_{1}\left(\frac{1}{1-r}\right),
$$

that is from (14) and (16) we obtain

$$
\int_{r_{0}}^{1} \alpha^{\prime}(\nu(r, \varphi)) \beta_{1}\left(\frac{1}{1-r}\right) d \nu(r, \varphi)<+\infty .
$$

Since $\ln \frac{1}{W_{F}(x)}=v(x) \in V(1)$ and $x=\nu(r, \varphi)$ is a solution of the equation $-v^{\prime}(x)+r=0$, we have $r=v^{\prime}(\nu(r, \varphi))$ and hence it follows that

$$
\int_{r_{0}}^{\infty} \alpha^{\prime}(\nu(r, \varphi)) \beta_{1}\left(\frac{1}{1-v^{\prime}(\nu(r, \varphi))}\right) d \nu(r, \varphi)<+\infty
$$

i.e.

$$
\int_{x_{0}}^{\infty} \alpha^{\prime}(x) \beta_{1}\left(\frac{1}{1-v^{\prime}(x)}\right) d x<+\infty
$$

From a theorem proved in [8] it follows that if $a(x)$ and $\mu(x)$ are continuous functions on $(0,+\infty),-\infty \leq A<a(x)<B \leq+\infty, \mu(x) \searrow \mu \geq 0$ as $x \rightarrow+\infty$, and for a positive function $f$ on $(A, B)$ the function $f^{1 / p}$ with $p>1$ is convex on $(A, B)$, then

$$
\int_{0}^{y} \mu(x) f\left(\frac{1}{x} \int_{0}^{x} a(t) d t\right) d x \leq\left(\frac{p}{p-1}\right)^{p} \int_{0}^{y} \mu(x) f(a(x)) d x, \quad y \leq+\infty .
$$

We choose $\mu(x)=\alpha^{\prime}(x), a(x)=v^{\prime}(x), f(x)=\beta_{1}\left(\frac{1}{1-x}\right)$ and show that the function $f^{1 / p}$ is convex for some $p>1$.

It is easy to see that $f^{1 / p}$ is convex for $p>1$ if $f(x) f^{\prime \prime}(x)-\frac{p-1}{p}\left(f^{\prime}(x)\right)^{2} \geq 0$ that is if

$$
\beta_{1}\left(\frac{1}{1-x}\right) \beta_{1}^{\prime \prime}\left(\frac{1}{1-x}\right)+2(1-x) \beta_{1}\left(\frac{1}{1-x}\right) \beta_{1}^{\prime}\left(\frac{1}{1-x}\right) \geq \frac{p-1}{p}\left(\beta_{1}^{\prime}\left(\frac{1}{1-x}\right)\right)^{2}
$$

and thus, if

$$
\beta_{1}(t) \beta_{1}^{\prime \prime}(t)+\frac{2}{t} \beta_{1}(t) \beta_{1}^{\prime}(t) \geq \frac{p-1}{p}\left(\beta_{1}^{\prime}(t)\right)^{2} .
$$

Since $\beta_{1}(t)=\int_{t}^{\infty} \frac{d x}{\beta(x)}$, the last inequality holds if

$$
\left(\beta^{\prime}(t)-\frac{2 \beta(t)}{t}\right) \int_{t}^{\infty} \frac{d x}{\beta(x)} \geq \frac{p-1}{p}
$$


Since $\beta^{\prime}(t)-\frac{2 \beta(t)}{t} \geq \frac{h \beta(t)}{t}>0$, we have

$$
\left(\beta^{\prime}(t)-\frac{2 \beta(t)}{t}\right) \int_{t}^{\infty} \frac{d x}{\beta(x)} \geq\left(\beta^{\prime}(t)-\frac{2 \beta(t)}{t}\right) \int_{t}^{2 t} \frac{d x}{\beta(x)} \geq\left(\beta^{\prime}(t)-\frac{2 \beta(t)}{t}\right) \frac{t}{\beta(t)} \geq h .
$$

Therefore, choosing $p>1$ such that $h-\frac{p-1}{p} \geq 0$, we get inequality (19), i. e. the function $\beta_{1}^{1 / p}\left(\frac{1}{1-x}\right)$ is convex and in view of (18)

$$
\int_{0}^{\infty} \alpha^{\prime}(x) \beta_{1}\left(\frac{1}{1-\frac{1}{x} \int_{0}^{x} v^{\prime}(t) d t}\right) d x \leq\left(\frac{p}{p-1}\right)^{p} \int_{0}^{\infty} \alpha^{\prime}(x) \beta_{1}\left(\frac{1}{1-v^{\prime}(x)}\right) d x .
$$

Since $\int_{x_{0}}^{x} v^{\prime}(t) d t=\ln \frac{1}{\left.W_{F}(x)\right)}$, from (17) and (20) we obtain 15 . Theorem 2 is proved.

\section{REFERENCES}

1. Yu. V. Linnik and I. V. Ostrovskii, Decompositon of random variables and vectors, Nauka, Moscov, 1972 (Russian).

2. Yu. M. Gal' and M. M. Sheremeta, Belonging of analytic functions to a covergence class, Dop. AN URSR, Ser. A (1985), no. 7, 11-14 (Ukrainian).

3. G. R. MacLane, Asymptotic values of holomorphic functions, Rice Univ. Studies 49 (1963), no. $1,1-83$.

4. V. M. Sorokivskii, On the growth of characteristic functions of probability laws, Drogobych (1980), 20 p. Dep. in VINITI 17.12.80, N 5330-80 DEP (Russian).

5. L. V. Kulyavets', O. M. Mulyava, and M. M. Sheremeta, On belonging of characteristic functions of probability laws to a convergence class, Bull. Soc. Sci. Lett. Lodz., Ser Rech. Deform. 63 (2013), no. 2, 9-22.

6. M. M. Sheremeta, On two classes of positive functions and the belonging to them of main characteristics of entire functions, Mat. Stud. 19 (2003), no. 1, 75-82.

7. E. Seneta, Regularly varying functions, Lect. Notes Math. 508, Springer-Verlag, Berlin, 1976.

8. О. М. Мулява, Інтегралъний аналог одного узагалъненнл нерівності Гарді та його застосування, Укр. мат. журн. 58 (2006), no. 9, 1271-1275; English version: O. M. Mulyava, Integral analog of one generalization of the Hardy inequality and its applications, 58 (2006), no. 9, 1441-1447. DOI: $10.1007 / \mathrm{s} 11253-006-0143-0$

Стаття: надійшла до редколегї 23.10.2018 доопрачвована 03.12.2018 прийнята до друку 26.12.2018 


\title{
ПРО НАЛЕЖНІСТЬ АНАЛІТИЧНИХ В ОДИНИЧНОМУ КРУЗІ ХАРАКТЕРИСТИЧНИХ ФУНКЦІЙ ЙМОВІРНІСНИХ ЗАКОНІВ ДО УЗАГАЛЬНЕНОГО КЛАСУ ЗБІЖНОСТІ
}

\author{
Оксана МУЛЯВА ${ }^{1}$, Мирослав ШЕРЕМЕТА $^{2}$ \\ ${ }^{1}$ Киёвсъкий націоналъний університет харчових технологій \\ Володимирівсъка 68, Киёв, 01004 \\ e-mail: info@nuft.edu.ua \\ 2 Лъвівсъкий націоналъний університет ім. І. Франка, \\ Університетсъка 1, 79000, Лъвів \\ e-mail: m.m.sheremeta@gmail.com
}

Для неперервних зростаючих до $+\infty$ на $\left[x_{0},+\infty\right)$ функцій $\alpha$ і $\beta$ будемо говорити, що аналітична в $\mathbb{D}=\{z:|z|<1\}$ характеристична функція $\varphi$ ймовірнісного закону $F$ належить до узагальненого $\alpha \beta$-класу збіжності, якщо $\int_{r_{0}}^{1} \frac{\alpha(\ln M(r, \varphi))}{(1-r)^{2} \beta\left(\frac{1}{1-r}\right)} d r<+\infty$. Знайдено умови на $\alpha, \beta$ і $F$, за яких функція $\varphi$ належить до узагальненого $\alpha \beta$-класу збіжності тоді і тільки тоді, коли $\int_{x_{0}}^{\infty} \alpha^{\prime}(x) \beta_{1}\left(\frac{x}{\ln \left(W_{F}(x) e^{x}\right)}\right) d x<+\infty$, де $\beta_{1}(x)=\int_{x}^{\infty} \frac{d t}{\beta(t)}$ i $W_{F}(x)=1-F(x)+F(-x)$.

Ключові слова: аналітична функція, ймовірнісний закон, характеристична функція, узагальнений клас збіжності. 